\title{
Probiotic Lactobacillus gasseri SBT2055 improves glucose tolerance and reduces body weight gain in rats by stimulating energy expenditure
}

\author{
Bungo Shirouchi ${ }^{1}$, Koji Nagao ${ }^{2}$, Minami Umegatani ${ }^{1}$, Aya Shiraishi ${ }^{1}$, Yukiko Morita ${ }^{1}$, Shunichi Kai ${ }^{2}$, \\ Teruyoshi Yanagita $^{3}$, Akihiro Ogawa ${ }^{4}$, Yukio Kadooka ${ }^{4}$ and Masao Sato ${ }^{1 *}$ \\ ${ }^{1}$ Laboratory of Nutrition Chemistry, Department of Bioscience and Biotechnology, Faculty of Agriculture, Graduate School, \\ Kyushu University, 6-10-1 Hakozaki, Higashi-ku, Fukuoka 812-8581, Japan \\ ${ }^{2}$ Laboratory of Nutrition Biochemistry, Department of Applied Biochemistry and Food Science, Saga University, 1 Honjo, \\ Saga 840-8502, Japan \\ ${ }^{3}$ Faculty of Health and Nutrition Science, Nishikyushu University, 4490-9 Ozaki, Kanzaki, Saga 842-8585, Japan \\ ${ }^{4}$ Milk Science Research Institute, Megmilk Snow Brand Co. Ltd, 1-1-2 Minamidai, Kawagoe, Saitama 350-1165, Japan \\ (Submitted 22 December 2015 - Final revision received 28 April 2016 - Accepted 30 April 2016 - First published online 8 June 2016)
}

\section{Abstract}

Probiotic Lactobacillus gasseri SBT2055 (LG2055) reduces postprandial TAG absorption and exerts anti-obesity effects in rats and humans; however, the underlying mechanisms are not fully understood. In the present study, we addressed the mechanistic insights of the anti-obesity activity of LG2055 by feeding Sprague-Dawley rats diets containing skimmed milk fermented or not by LG2055 for 4 weeks and by analysing energy expenditure, glucose tolerance, the levels of SCFA in the caecum and serum inflammatory markers. Rats fed the LG2055-containing diet demonstrated significantly higher carbohydrate oxidation in the dark cycle (active phase for rats) compared with the control group, which resulted in a significant increase in energy expenditure. LG2055 significantly reduced cumulative blood glucose levels (AUC) compared with the control diet after 3 weeks and increased the molar ratio of butyrate:total SCFA in the caecum after 4 weeks. Furthermore, the LG2055supplemented diet significantly reduced the levels of serum amyloid P component - an indicator of the inflammatory process. In conclusion, our results demonstrate that, in addition to the inhibition of dietary TAG absorption reported previously, the intake of probiotic LG2055 enhanced energy expenditure via carbohydrate oxidation, improved glucose tolerance and attenuated inflammation, suggesting multiple additive and/or synergistic actions underlying the anti-obesity effects exerted by LG2055.

Key words: Lactobacillus gasseri SBT2055: Energy expenditure: Glucose tolerance: Obesity

The use of probiotic strains such as lactobacilli and bifidobacteria is increasingly expanding because of their beneficial effects ${ }^{(1)}$. Lactobacillus gasseri SBT2055 (LG2055) is a representative of probiotic lactic acid bacteria isolated from the gastrointestinal tract in Japan ${ }^{(2,3)}$, which has been shown to improve intestinal microflora and metabolism ${ }^{(4)}$. Previous studies have indicated that LG2055 decreases lymphatic TAG absorption and increases faecal fatty acid excretion in rats ${ }^{(5)}$, decreases postprandial TAG absorption in humans ${ }^{(6)}$ and exerts anti-obesity effect both in animals $^{(5,7-9)}$ and in humans ${ }^{(10,11)}$. However, the underlying mechanisms are not quite clear. Other probiotic bacteria have also been reported to improve metabolism and exert anti-obesity effects in rodents ${ }^{(12-25)}$. The key mechanisms include induction of lipolysis via production of trans-10,cis-12-conjugated linoleic acid $^{(12,13)}$, increase in sympathetic nerve activity ${ }^{(14)}$ and suppression of fat deposition via increased expression of angiopoietin-like 4, a circulating inhibitor of lipoprotein lipase ${ }^{(15,17)}$. Furthermore, several Lactobacillus strains have been shown to induce transcriptional activation of fatty acid $\beta$-oxidation-related genes in the liver ${ }^{(19-21,23)}$ and muscle ${ }^{(21)}$, while inhibiting the transcription of fatty acid synthase in the liver ${ }^{(24)}$, and to improve insulin sensitivity ${ }^{(21,22)}$ and glucose tolerance ${ }^{(25)}$. However, there is no direct evidence of the effects of probiotics on energy expenditure, which is closely related to the metabolism of macronutrients, especially carbohydrates and fats.

Obesity develops as a consequence of chronic deregulation in macronutrient oxidation levels ${ }^{(26,27)}$. Therefore, to gain the mechanistic insights of anti-obesity effects exerted by LG2055, it is necessary to evaluate the relationship between energy and macronutrient metabolism. Several methods have been used to assess the balance between nutrient oxidation and energy generation, such as indirect calorimetry, which has been applied to estimate net rates of carbohydrate and fat oxidation in humans ${ }^{(26,28)}$ and rodents ${ }^{(29,30)}$ based on $\mathrm{VO}_{2}$ and carbon

Abbreviations: CRP, C-reactive protein; GIP, glucose-dependent insulinotropic polypeptide; GLP-1, glucagon-like peptide-1; GPR41, G protein-coupled receptors 41; SAP, serum amyloid P component; SM, skimmed milk.

* Corresponding author: M. Sato, fax +8192642 3004, email masaos@agr.kyushu-u.ac.jp 
dioxide production. Another widely used convenient and reliable method is the oral glucose tolerance test (OGTT), which can help diagnose glucose intolerance and insulin resistance ${ }^{(31)}$.

Obesity is a part of the metabolic syndrome, which, according to previous reports, is associated with low-grade inflammation, shown to play a role in the pathogenesis of glucose disorders $^{(32,33)}$. Thus, insulin resistance and type 2 diabetes are characterised by higher levels of inflammatory markers including cytokines and acute-phase reactants ${ }^{(34,35)}$. Previous studies have shown that LG2055 reduces serum levels of soluble intercellular adhesion molecule- 1 induced by inflammatory cytokines in rats ${ }^{(8)}$ and down-regulates mRNA expression of C-C motif chemokine ligand 2 ( $\mathrm{CCl} 2$ ), also known as monocyte chemoattractant protein 1 , in adipose tissue of mice ${ }^{(9)}$, indicating that LG2055 has antiinflammatory activity. However, the effect of LG2055 on the level of acute-phase reactants has not been investigated.

In the present study, we addressed the mechanistic insights of LG2055 anti-obesity activity by evaluating energy and glucose metabolism, as well as measuring the levels of serum amyloid $\mathrm{P}$ component (SAP), an acute-phase reactant, in rats.

\section{Methods}

Preparation of milk fermented by Lactobacillus gasseri SBT2055

Milk fermented by LG2055 was prepared as described previously $^{(5)}$. In brief, skimmed milk (SM) powder (Megmilk Snow Brand Co. Ltd) was dissolved in de-ionised water, supplemented with yeast extract and sterilised at $95^{\circ} \mathrm{C}$ for $30 \mathrm{~min}$. After inoculation with LG2055, the mixture was incubated at $37^{\circ} \mathrm{C}$ for $16 \mathrm{~h}$, freeze-dried and used for subsequent experiments. Non-fermented SM prepared by treating SM powder in the same conditions without LG2055 was used as control. Chemical compositions of control SM $(34.7 \%$ protein, $0.9 \%$ fat, $52.6 \%$ carbohydrate, $7.9 \%$ ash and $3.9 \%$ moisture) and fermented SM (35.4\% protein, $0.9 \%$ fat, $52.6 \%$ carbohydrate, $7.7 \%$ ash and $3.4 \%$ moisture) were similar, except that the latter also contained $11.8 \mathrm{~g}$ lactic acid $/ 100 \mathrm{~g}$. The final concentration of viable LG2055 in the fermented SM-containing diet was $6 \times 10^{7}$ colony-forming unit/g diet.

\section{Animal experiments}

For the present study, 4-week-old male Sprague-Dawley rats (Kud:SD) were obtained from Kyudo. The rats were housed individually in metal cages in a temperature-controlled room $\left(24^{\circ} \mathrm{C}\right)$ under a $12 \mathrm{~h}$ light $-12 \mathrm{~h}$ dark cycle. Experimental diets were prepared according to the AIN-76 formula ${ }^{(36)}$ with some modifications and contained $(\mathrm{g} / \mathrm{kg}) 100$ fat (90 lard and 10 maize oil), 200 non-fermented SM powder (control diet) or LG2055-fermented SM powder (LG2055 diet), 125 casein, $150 \alpha$-maize starch, 50 cellulose, 3 DL-methionine, 35 mineral mixture (AIN-76), 10 vitamin mixture (AIN-76) and sucrose to $1000 \mathrm{~g}$. The protein concentration provided by fermented and non-fermented SM was $70 \cdot 8$ and $69.4 \mathrm{~g} / \mathrm{kg}$ diet, respectively. Diets containing high sucrose and lard rich in SFA were used to induce obesity and glucose intolerance.
In the experiment performed at Saga University, rats were allowed free access to commercial chow for a week, and then divided into the control and LG2055 groups ( $n$ 6). There was no significant difference in the initial body weight between the two groups (control, 139 (SEM 1) g; LG2055, 139 (SEM 1) g). The experimental diets were pair-fed to the rats. After 1 week, the animals were subjected to respiratory gas analysis, then anaesthetised with Somnopentyl ${ }^{\circledR}$ (Kyoritsu Seiyaku Corporation) and killed by aortic exsanguination.

In the experiment performed at Kyushu University, rats were acclimatised as described above and divided into the same groups ( $n$ 6); the initial body weight was not significantly different between the two groups (control, 141 (sEm 2) g; LG2055, 140 (sЕм 3) g). The experimental diets were pair-fed for 4 weeks. After 3 weeks, rats were analysed by OGTT. At the end of the feeding period, animals were subjected to a 9-h fasting period, anaesthetised with somnopentyl and killed by aortic exsanguination. The pancreas, liver, white adipose tissue (WAT; mesenteric, perirenal, retroperitoneal, epididymal and subcutaneous), quadriceps femoris, pancreas and caecum were immediately excised and weighed. EDTA-containing plasma was prepared by blood centrifugation at $1750 \boldsymbol{g}$ for $15 \mathrm{~min}$, and DPP-IV inhibitor (EMD Millipore Co.) was added to measure glucagon-like peptide-1 (GLP-1) levels. Serum was separated by incubating blood samples for $30 \mathrm{~min}$ at room temperature. The samples were maintained at $-30^{\circ} \mathrm{C}$ until analysis.

All animal experiments were conducted according to the Guidelines for Animal Experiments of Saga University and Kyushu University, as well as the law (no. 105) and notification (no. 6) of the government of Japan. The animal protocols were approved by the review committees of Saga University (authorisation no. 19-002-1) and Kyushu University (authorisation no. A22-159-1).

\section{Respiratory gas analysis}

After 1 week of feeding the diets, each rat was placed into a metabolic chamber $\left(210 \mathrm{~cm}^{2}\right.$ in square, $11.5 \mathrm{~cm}$ in height) for $21 \mathrm{~h}$ to measure $\mathrm{VO}_{2}$ and the RQ. The system consisted of six acrylic metabolic chambers, a MS (model WSMR-1400), gas sampler (model WGSS-1000) and switching controller (model WMSC-2000); all instrumentation and software were obtained from Arco System. Room air was pumped through the chambers at a rate of $1.7 \mathrm{l} / \mathrm{min}$; expired air was dried by passing through a thin cotton wool-containing column and directed to a MS. The air from each chamber was sampled for $1 \mathrm{~min}$ every $7 \mathrm{~min}$, and the data were stored in a spreadsheet. The RQ, carbohydrate and fat oxidation, and energy production rates were calculated by the software using the following formulae:

$$
\mathrm{RQ}=\mathrm{VCO}_{2} / \mathrm{VO}_{2}
$$

carbohydrate oxidation $=4 \cdot 51 \times \mathrm{VCO}_{2}-3 \cdot 18 \times \mathrm{VO}_{2}$,

fat oxidation $=1.67 \times\left(\mathrm{VCO}_{2}-\mathrm{VO}_{2}\right)$,

energy production rate $=(2 \cdot 96 \times \mathrm{RQ}+2 \cdot 49) \times \mathrm{VO}_{2}$.

where $\mathrm{VCO}_{2}$ is carbon dioxide exhaustion. 
During the analysis, rats were pair-fed diets and had free access to water. The experiment was carried out in a separate room to avoid animal stress.

\section{Oral glucose tolerance test}

After 3 weeks of feeding, rats were subjected to $16 \mathrm{~h}$ of fasting and then orally administered a glucose bolus $(2 \mathrm{~g} / \mathrm{kg}$ body weight). Blood was drawn from the tail vein at $0,15,30,60,90$ and $120 \mathrm{~min}$ after bolus administration, and glucose levels were measured using an Accu-Chek ${ }^{\circledR}$ Aviva Nano blood glucose meter (Roche Diagnostics). The AUC of blood glucose concentration (0-120 min) was calculated using the trapezoidal rule.

\section{Analysis of metabolic parameters}

The levels of blood HbA1c were measured using a commercial kit based on the latex-agglutination assay (RAPIDIA ${ }^{\circledR}$ Auto HbA1c-L; Fujirebio Inc.). Plasma TAG, cholesterol, free fatty acids and glucose levels were measured using enzyme assay kits (Triglyceride E-Test, Cholesterol E-Test, NEFA C-Test and Glucose CII-Test, respectively; Wako Pure Chemicals). Plasma levels of insulin, glucagon, glucose-dependent insulinotropic polypeptide (GIP) and GLP-1 and serum levels of fatty acidbinding protein 4 (FABP4) and SAP were measured using commercial ELISA kits (rat insulin ELISA; Shibayagi Co. Ltd, rat/mouse GIP total ELISA; EMD Millipore Co., rat glucagon ELISA kit and rat GLP-1 ELISA kit; Wako Pure Chemicals, CircuLex Rat FABP4/A-FABP ELISA kit; CycLex Co. Ltd, Serum Amyloid P Rat ELISA kit; Abcam). Glycogen levels in the liver and muscle were determined according to the method of Lo et al. ${ }^{(37)}$.

\section{Analysis of caecal lactic acid and SCFA}

The caecal levels of lactic acid and SCFA were determined as described elsewhere ${ }^{(38)}$ with some modifications. In brief, caecal content was homogenised in sterile water, de-proteinised with $60 \% \mathrm{HClO}_{4}$ and separated by centrifugation at $8500 \boldsymbol{g}$ for $10 \mathrm{~min}$ at $4^{\circ} \mathrm{C}$. The supernatant was filtered through a cellulose acetate membrane filter $(0.45 \mu \mathrm{m}$; Advantec), and individual SCFA were determined by the bromothymol blue (BTB) post-column method using an HPLC system (SHIMADZU SCL-10A; Shimadzu). The analytical conditions were as follows: column, TSKgel OApak-A $(7 \mu \mathrm{m}, 7.8 \mathrm{~mm}$ i.d. $\times 30 \mathrm{~cm}$; Tosoh Co.); guard column, TSKgel OApak-P $(10 \mu \mathrm{m}, 6.0 \mathrm{~mm}$ i.d. $\times 4 \mathrm{~cm}$; Tosoh Co. $)$; eluent and flow rate, $5 \mathrm{~mm}^{-} \mathrm{HClO}_{4}$ at $0.7 \mathrm{ml} / \mathrm{min}$; column temperature, $60^{\circ} \mathrm{C}$; reagents and flow rate, $0 \cdot 1 \mathrm{~mm}-\mathrm{BTB}$ and $15 \mathrm{~mm}-\mathrm{Na}_{2} \mathrm{HPO}_{4}$ at $1.2 \mathrm{ml} / \mathrm{min}$; and detector wavelength, $445 \mathrm{~nm}$. The injection volume was $25 \mu \mathrm{l}$, and the total run time was $40 \mathrm{~min}$. Total SCFA present the sum of acetate, propionate and butyrate levels.

\section{Statistical analysis}

All values are expressed as means with their standard errors. Differences between the two groups were determined by
Student's $t$ test and were considered statistically significant at $P<0.05$.

\section{Results}

Effects of the LG2055 diet on nutrient oxidation and energy expenditure

The effects of the LG2055 diet on energy metabolism were assessed on the basis of respiratory gas analysis in rats fed the same amount of diets (control group, $10 \cdot 7$ (SEM 0.1) g; LG2055 group, $10 \cdot 8$ (SEM 0.1)g). The LG2055 group demonstrated significantly higher carbohydrate oxidation in the dark cycle (active phase for rats) compared with the control group, which resulted in a significant increase in energy expenditure (Fig. 1(a) and (c)). Moreover, the LG2055 diet tended to induce fat oxidation in the light cycle (resting phase for rats) (Fig. 1(b)), although the effect was not statistically significant.

\section{Effects of the LG2055 diet on morphometric and metabolic parameters}

The two groups of rats did not differ in their food intake after the 4 -week feeding period. Body weight gain was significantly lower in the LG2055 diet-fed rats (Table 1). However, there were no differences between the two groups in terms of organ weights (liver, quadriceps femoris, pancreas, caecum and WAT), plasma parameters (TAG, cholesterol, free fatty acid, glucose, insulin, glucagon, GIP and GLP-1), blood HbA1c, serum FABP 4 and glycogen content of the liver and muscle (Table 1). At the same time, SAP levels were significantly reduced in the LG2055 diet-fed rats. Table 2 shows that the contents of lactic acid, the ratios of acetate:total SCFA and propionate:total SCFA in the caecum did not differ between the two groups, but the propionate + butyrate:total SCFA ratio tended to be higher $(P=0.085)$ and the butyrate:total SCFA ratio was significantly higher $(P<0.05)$ in the LG2055 group. Total butyrate content in the caecum also tended to increase (7.02 (sEM 1.08) $\mu \mathrm{mol} / \mathrm{g}$ in the control group $v$. 8.58 (sEM 0.46$) \mu \mathrm{mol} / \mathrm{g}$ in the LG2055 group), but the difference was not statistically significant.

\section{Effects of the LG2055 diet on postprandial glucose responses}

OGTT analysis indicated that the LG2055 diet tended to lower postprandial glucose levels in rats starting $15 \mathrm{~min}$ after bolus challenge compared with the control diet, resulting in a significant decrease in cumulative glucose levels (AUC, $P<0 \cdot 05$; Fig. 2 inset).

\section{Discussion}

In the present study, we addressed the mechanistic insights of anti-obesity effects exerted by the probiotic lactic acid bacteria strain L. gasseri SBT2055. The results indicated that LG2055 enhanced energy expenditure and improved glucose tolerance, 


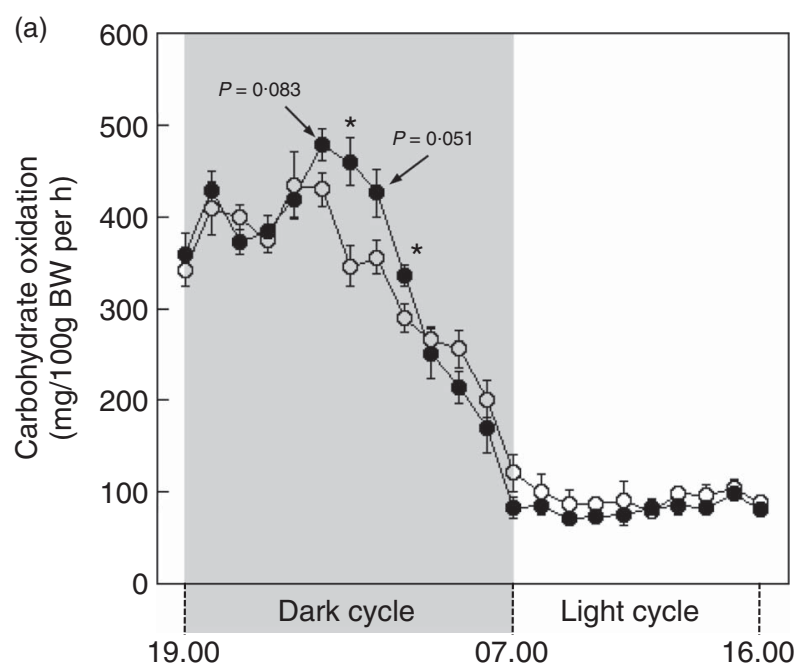

(b)

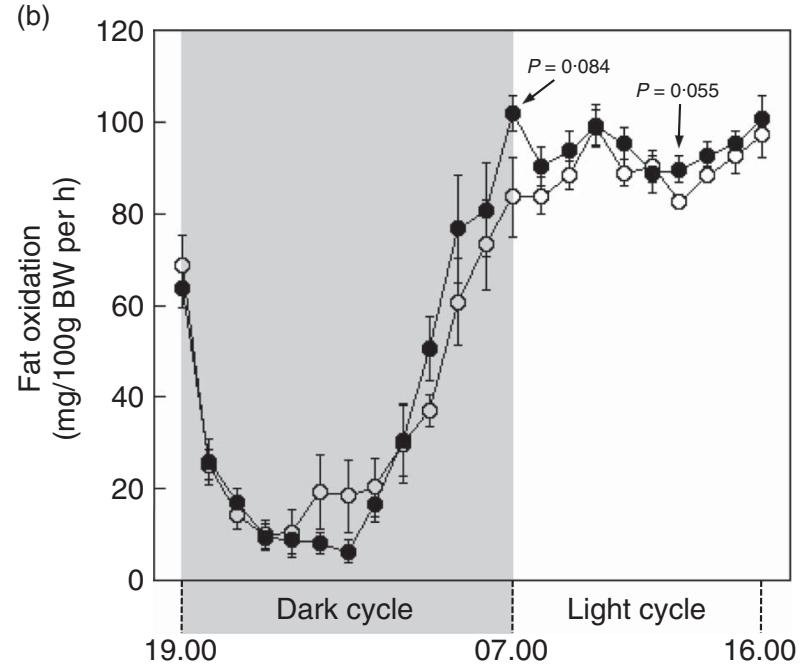

(c)

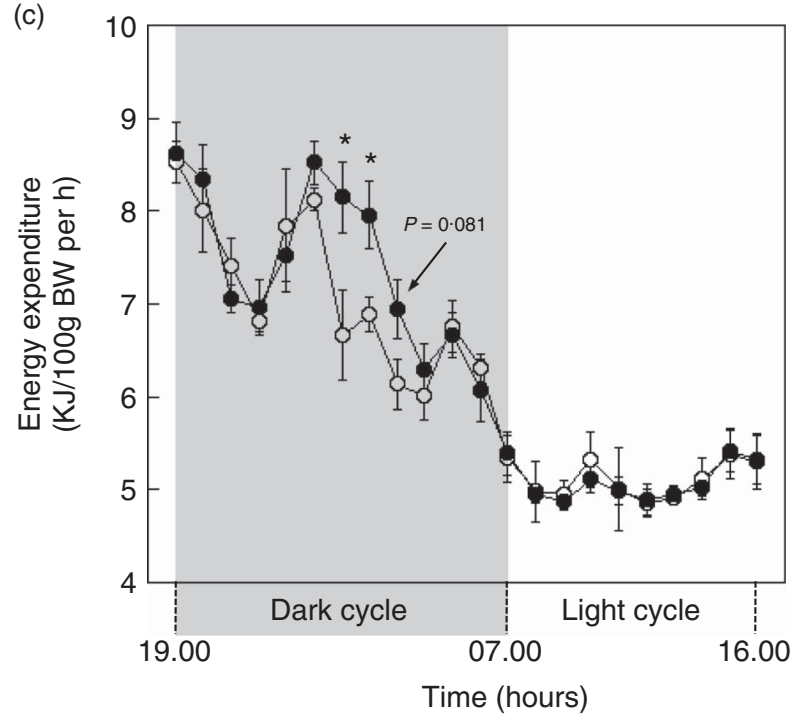

Fig. 1. Time course of the changes in carbohydrate oxidation (a), fat oxidation (b) and energy expenditure (c) in rats fed the control (-O-) diet or the LG2055 $(--)$ diet for 1 week. Values are means $(n 6)$, with their standard errors. * Mean values were significantly different from those of the control group $(P<0.05)$. BW, body weight. which correlates with previously shown reduction in postprandial TAG absorption ${ }^{(5,6)}$. We believe that the enhancement of energy expenditure via increase in carbohydrate oxidation (Fig. 1(a) and (c)) may have contributed to the LG2055-elicited anti-obesity effect (Table 1) and improvement in glucose tolerance (Fig. 2). Mammals utilise not only glucose, long-chain fatty acids and amino acids as energy sources, but also SCFA derived from colonic fermentation of dietary fibre by the gut microbiota. The association of microbial activity in the gastrointestinal tract with host energy homoeostasis and obesity pathogenesis is increasingly recognised ${ }^{(39,40)}$. Recently, a series of orphan $G$ protein-coupled receptors were shown to bind free fatty acids; among them, free fatty acid receptor 3 (FFA3/GPR41) is expressed in the intestine and sympathetic nervous system, and is activated by $\mathrm{SCFA}^{(41)}$ including propionate (C3) and butyrate (C4), which showed 9.6-fold and 11.9-fold higher receptor activation compared with acetate $(\mathrm{C} 2)^{(42)}$. GPR41 knockout mice exhibited lower energy expenditure and glucose tolerance compared with wild-type mice ${ }^{(43)}$. Kimura et al. ${ }^{(44)}$ reported that SCFA directly up-regulate the activity of the sympathetic nervous system via GPR41, and thereby enhance body energy expenditure in mice. In addition, Gao et $a l .{ }^{(45)}$ reported that dietary supplementation of sodium butyrate improves insulin sensitivity and increases energy expenditure in mice. In the present study, the LG2055 diet tended to increase the content of caecal butyrate and decrease that of acetate, which is less potent in GPR41 activation, resulting in a significantly elevated (39.4\%) ratio of butyrate: total SCFA (Table 2). These results suggest that the increase in butyrate production in the caecum by LG2055 may enhance energy expenditure and improve glucose tolerance via GPR41 activation. Further controlled studies are needed to determine whether and how changes in SCFA profile of the caecum by LG2055 are reflected in SCFA levels of portal and aortic sera, and whether GPR41 is activated by LG2055. Considering that other probiotic bacteria also inhibit obesity development in rodents ${ }^{(12-25)}$, it should be interesting to investigate whether their anti-obesity effects are associated with the enhancement of butyrate production. Furthermore, it is known that incretin hormones such as GIP and GLP-1 control energy metabolism ${ }^{(46)}$. Tolhurst et al. ${ }^{(47)}$ reported that SCFA stimulate GLP-1 secretion via GPR41 in primary mouse colonic cells. Moreover, incretin hormones are released from the intestine in response to food ingestion ${ }^{(46)}$. However, in the present study, plasma levels of GIP and GLP-1 after $9 \mathrm{~h}$ of fasting did not differ between the groups (Table 1). These results may reflect that unlike prebiotics the change of SCFA profile by probiotics is milder.

Probiotics and prebiotics affect fermentation processes in the host caecum and regulate SCFA synthesis. Several studies have demonstrated that consumption of a diet high in inulin $^{(48)}$, oligofructose ${ }^{(49)}$ or their combination ${ }^{(50)}$ reduced body weight by lowering energy intake in rats. Dietary prebiotic fibres containing inulin and oligofructose in a $1: 1$ ratio altered energy intake by increasing satiety hormones but not energy expenditure; however, as caecal SCFA levels were not measured in that study ${ }^{(50)}$, the contribution of SCFA to the reduction of body weight by prebiotics remains unclear. Together, these findings indicate that the reduction of 
Table 1. Effects of diets containing skimmed milk (control) and fermented milk (LG2055) on morphometric and metabolic parameters of rats

(Mean values with their standard errors)

\begin{tabular}{|c|c|c|c|c|}
\hline & \multicolumn{2}{|c|}{ Control } & \multicolumn{2}{|c|}{ LG2055 } \\
\hline & Mean & SEM & Mean & SEM \\
\hline Food intake $(\mathrm{g} / \mathrm{d})$ & $20 \cdot 6$ & 0.2 & $20 \cdot 6$ & 0.2 \\
\hline Body weight gain (g) & 175 & 7 & 157 & $4^{*}$ \\
\hline \multicolumn{5}{|l|}{ Mass $(\mathrm{g})$} \\
\hline Liver & $10 \cdot 5$ & 0.8 & $10 \cdot 7$ & 0.5 \\
\hline Quadriceps femoris & 4.88 & 0.23 & 4.72 & 0.30 \\
\hline Pancreas & 0.631 & 0.058 & 0.554 & 0.019 \\
\hline Caecum with contents & $3 \cdot 31$ & 0.27 & 2.83 & 0.11 \\
\hline \multicolumn{5}{|l|}{ White adipose tissues } \\
\hline Mesenteric & 3.64 & 0.25 & $3 \cdot 20$ & 0.22 \\
\hline Perirenal & 1.23 & 0.17 & $1 \cdot 16$ & 0.20 \\
\hline Retroperitoneal & 4.31 & 0.26 & 4.47 & 0.69 \\
\hline Epididymal & 5.00 & 0.36 & 4.63 & 0.58 \\
\hline Subcutaneous & $13 \cdot 0$ & 0.9 & $12 \cdot 5$ & 1.3 \\
\hline Blood HbA1c (\%) & $6 \cdot 64$ & 0.73 & $6 \cdot 26$ & 0.41 \\
\hline \multicolumn{5}{|l|}{ Plasma parameters } \\
\hline TAG $(\mathrm{mg} / \mathrm{l})$ & 1053 & 251 & 1425 & 190 \\
\hline Cholesterol $(\mathrm{mg} / \mathrm{l})$ & 648 & 80 & 666 & 89 \\
\hline Free fatty acid (mEq/l) & 0.394 & 0.052 & 0.464 & 0.049 \\
\hline Glucose $(\mathrm{mg} / \mathrm{l})$ & 2220 & 139 & 2139 & 126 \\
\hline Insulin (ng/ml) & 4.48 & 0.81 & 5.04 & 1.19 \\
\hline Glucagon (pg/ml) & 557 & 87 & 544 & 75 \\
\hline GIP $(\mathrm{pg} / \mathrm{ml})$ & 74.7 & 11.8 & $74 \cdot 8$ & $7 \cdot 1$ \\
\hline GLP-1 $(\mathrm{ng} / \mathrm{ml})$ & 2.92 & 0.61 & 3.66 & 0.54 \\
\hline Serum FABP4 $(\mathrm{ng} / \mathrm{ml})$ & 586 & 133 & 533 & 84 \\
\hline Serum amyloid P component $(\mu \mathrm{g} / \mathrm{ml})$ & 192 & 6 & 165 & $8^{*}$ \\
\hline Liver glycogen (mg/whole liver) & 259 & 54 & 275 & 86 \\
\hline Muscle glycogen (mg/whole quadriceps femoris) & $2 \cdot 26$ & 0.20 & $2 \cdot 70$ & 0.36 \\
\hline
\end{tabular}

HbA1c, glycated Hb; GIP, glucose-dependent insulinotropic polypeptide; GLP-1, glucagon-like peptide-1; FABP4, fatty acid-binding protein 4.

${ }^{*}$ Mean values were significantly different from those of the control group $(P<0.05)$.

Table 2. Effects of diets containing skimmed milk (control) and fermented milk (LG2055) on caecal lactic acid contents, caecal SCFA contents and molar SCFA ratios in rats†

(Mean values with their standard errors)

\begin{tabular}{|c|c|c|c|c|}
\hline & \multicolumn{2}{|c|}{ Control } & \multicolumn{2}{|c|}{ LG2055 } \\
\hline & Mean & SEM & Mean & SEM \\
\hline Caecal lactic acid ( $\mu \mathrm{mol} / \mathrm{g}$ content) & 2.34 & 0.60 & $2 \cdot 16$ & 0.33 \\
\hline \multicolumn{5}{|l|}{ Caecal SCFA ( $\mu \mathrm{mol} / \mathrm{g}$ content) } \\
\hline Acetate & $62 \cdot 5$ & 7.7 & $51 \cdot 7$ & 4.6 \\
\hline Propionate & $15 \cdot 3$ & 1.4 & $15 \cdot 5$ & 1.0 \\
\hline$n$-Butyrate & 7.02 & 1.08 & 8.58 & 0.46 \\
\hline Propionate $+n$-butyrate & $22 \cdot 3$ & $2 \cdot 3$ & $24 \cdot 1$ & $1 \cdot 2$ \\
\hline Total & 84.7 & 8.6 & $75 \cdot 8$ & 5.5 \\
\hline \multicolumn{5}{|l|}{ Molar SCFA ratio (\%) } \\
\hline Acetate:total SCFA & $73 \cdot 3$ & 2.5 & $67 \cdot 8$ & 1.6 \\
\hline Propionate:total SCFA & 18.5 & 1.8 & $20 \cdot 7$ & $1 \cdot 2$ \\
\hline$n$-Butyrate:total SCFA & 8.25 & 1.04 & 11.5 & $0.7^{\star}$ \\
\hline Propionate $+n$-butyrate:total SCFA & $26 \cdot 7$ & 2.5 & $32 \cdot 2$ & 1.6 \\
\hline
\end{tabular}

* Mean values were significantly different from those of the control group $(P<0.05)$.

$\dagger$ Total SCFA (acetate, propionate and $n$-butyrate).

body weight by dietary fibres depends on energy intake rather than energy expenditure, suggesting that prebiotics and probiotics may prevent obesity through distinct mechanisms. Therefore, diet supplementation with a mixture of probiotics and prebiotics (synbiotics) may exert more powerful anti-obesity effects due to synergism in SCFA production with the change in intestinal flora and should be a focus of future studies.
It has been proposed that low-grade inflammation is a feature of the metabolic syndrome, which may be promoted by the release of various inflammatory mediators from adipose tissue ${ }^{(32)}$. Previous cross-sectional studies have shown that insulin resistance and type 2 diabetes are associated with higher levels of pro-inflammatory cytokines and acute-phase reactants such as C-reactive protein $(\mathrm{CRP})^{(34,35)}$, which is consistent with the observation that lipopolysaccharide (LPS) presence results 


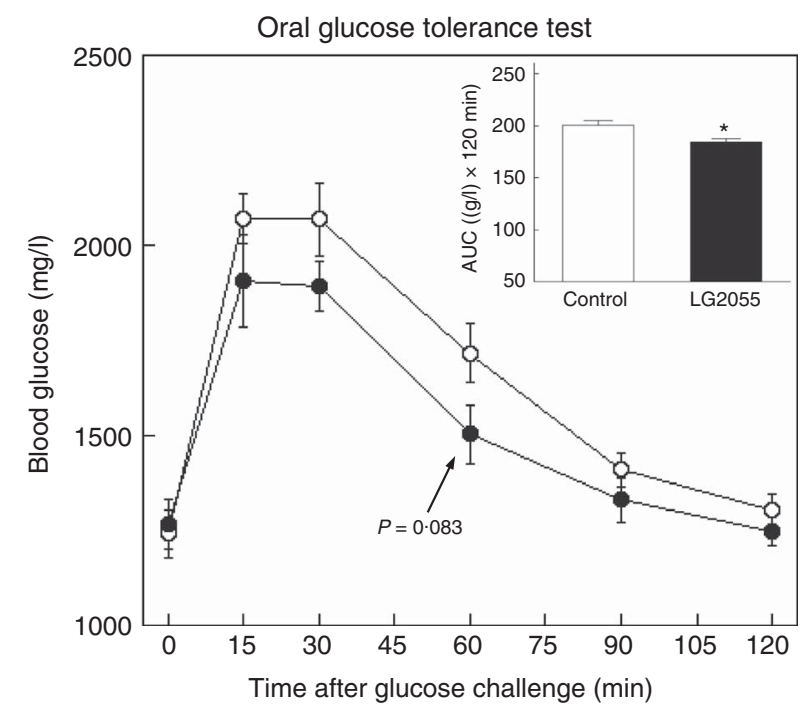

Fig. 2. Glucose tolerance in rats fed the control (- - ) diet or the LG2055 (-) diet for 3 weeks. Blood glucose was determined after $16 \mathrm{~h}$ of fasting. Following oral glucose administration, blood glucose levels were measured at the indicated intervals. The inset shows the AUC for each group. Values are means ( $n$ 6), with their standard errors. * Mean values were significantly different from those of the control group $(P<0.05)$.

in the amplification of inflammatory cascades via CRP production $^{(51)}$. Therefore, circulating CRP levels are used as a biomarker to assess inflammatory status ${ }^{(52)}$. However, in rats, serum CRP concentration is much higher compared with other species, exceeding even its maximal acute phase levels in humans ${ }^{(53)}$, which precludes the use of rat models in studies of CRP-associated inflammatory mechanisms. SAP is an acutephase protein, which shares approximately $60 \%$ homology with $\mathrm{CRP}^{(53,54)}$ and has comparable serum levels in rats and humans. Besides, rat SAP does not function as an acute-phase reactant in response to exogenous inflammatory stimuli such as casein or croton-oil injections ${ }^{53)}$, which is similar to human but different from mouse $\mathrm{SAP}^{(53)}$, suggesting that the findings in rats can be extrapolated to humans. SAP binds to gram-negative bacteria expressing LPS ${ }^{(55,56)}$, indicating that SAP levels are indices for infection of gram-negative bacteria and LPS influx into the body. Several studies have shown that low-grade inflammation is defined as a 2- to 4-fold increases in circulating inflammatory acute-phase proteins ${ }^{(57,58)}$. The normal range of SAP in rat and human sera is $10-50 \mu \mathrm{g} / \mathrm{ml}^{(53,54)}$. In the present study, we found that the LG2055 diet significantly reduced serum levels of SAP (192 (SEM 6) $\mu \mathrm{g} / \mathrm{ml}$ in the control group $v .165$ (SEM 8) $\mu \mathrm{g} / \mathrm{ml}$ in the LG2055 group), suggesting that LG2055 can prevent low-grade inflammation associated with obesity and glucose metabolism disorders.

In conclusion, we found that, in addition to the inhibition of dietary TAG absorption reported previously, probiotic LG2055 enhanced energy expenditure via stimulation of carbohydrate oxidation, improved glucose tolerance and reduced the levels of pro-inflammatory mediator SAP in rats. Considering that these effects correlate with the reduction of body weight gain, our findings suggest multiple actions activated by LG2055 that may work in synergy to prevent obesity.

\section{Acknowledgements}

The authors thank Editage (www.editage.jp) for English language editing.

The study was supported by Megmilk Snow Brand Co. Ltd (Saitama, Japan). The cost of English language editing was supported by a Research Grant for Young Investigators of Faculty of Agriculture, Kyushu University.

B. S. wrote the manuscript. B. S., K. N., M. U., A. S., Y. M. and S. K. carried out the experimental work and collected and analysed the data. B. S., K. N., T. Y., A. O., Y. K. and M. S. contributed to the study design, supervised the study and commented on the manuscript. All authors have read and approved the final version of the manuscript.

A. O. and Y. K. are employees of Megmilk Snow Brand Co. Ltd. There are no other patents, products in development or marketed products to declare. All other authors have no conflicts of interest to declare.

\section{References}

1. Food and Agriculture Organization (2006) Probiotics in Food: Health and Nutritional Properties and Guidelines for Evaluation. Joint WHO/FAO Expert Consultation. FAO Food and Nutrition Paper, no. 85. Rome: FAO.

2. Seto Y, Kimura A, Akai Y, et al. (2003) Distribution of the Lactobacillus acidophilus complex in human fecal specimens examined by restriction fragment length polymorphism of the 16S rRNA genes. Biosci Microflora 22, 75-83.

3. Takahashi H, Fujita T, Suzuki Y, et al. (2006) Monitoring and survival of Lactobacillus gasseri SBT2055 in the human intestinal tract. Microbiol Immunol 50, 867-870.

4. Fujiwara S, Seto Y, Kimura A, et al. (2001) Establishment of orally-administered Lactobacillus gasseri SBT2055SR in the gastrointestinal tract of humans and its influence on intestinal microflora and metabolism. J Appl Microbiol 90, 343-352.

5. Hamad EM, Sato M, Uzu K, et al. (2009) Milk fermented by Lactobacillus gasseri SBT2055 influences adipocyte size via inhibition of dietary fat absorption in zucker rats. Br J Nutr 101, 716-724.

6. Ogawa A, Kadooka Y, Kato K, et al. (2014) Lactobacillus gasseri SBT2055 reduces postprandial and fasting serum non-esterified fatty acid levels in Japanese hypertriacylglycerolemic subjects. Lipids Health Dis 13, 36.

7. Sato M, Uzu K, Yoshida T, et al. (2008) Effects of milk fermented by Lactobacillus gasseri SBT2055 on adipocyte size in rats. Br J Nutr 99, 1013-1017.

8. Kadooka Y, Ogawa A, Ikuyama K, et al. (2011) The probiotic Lactobacillus gasseri SBT2055 inhibits enlargement of visceral adipocytes and upregulation of serum soluble adhesion molecule (sICAM-1) in rats. Int Dairy J 21, 623-627.

9. Miyoshi M, Ogawa A, Higurashi S, et al. (2014) Anti-obesity effect of Lactobacillus gasseri SBT2055 accompanied by inhibition of pro-inflammatory gene expression in the visceral adipose tissue in diet-induced obese mice. Eur J Nutr 53, 599-606.

10. Kadooka Y, Sato M, Imaizumi K, et al. (2010) Regulation of abdominal adiposity by probiotics (Lactobacillus gasseri SBT2055) in adults with obese tendencies in a randomized controlled trial. Eur J Clin Nutr 64, 636-643.

11. Kadooka Y, Sato M, Ogawa A, et al. (2013) Effect of Lactobacillus gasseri SBT2055 in fermented milk on abdominal adiposity in adults in a randomised controlled trial. Br J Nutr 110, 1696-1703. 
12. Lee HY, Park JH, Seok SH, et al. (2006) Human originated bacteria, Lactobacillus rhamnosus PL60, produce conjugated linoleic acid and show anti-obesity effects in diet-induced obese mice. Biochim Biophys Acta 1761, 736-744.

13. Lee K, Paek K, Lee HY, et al. (2007) Antiobesity effect of trans10,cis-12-conjugated linoleic acid-producing Lactobacillus plantarum PL62 on diet-induced obese mice. J Appl Microbiol 103, 1140-1146.

14. Tanida M, Shen J, Maeda K, et al. (2008) High-fat diet-induced obesity is attenuated by probiotic strain Lactobacillus paracasei ST11 (NCC2461) in rats. Obes Res Clin Pract 2, I-II.

15. Aronsson L, Huang Y, Parini P, et al. (2010) Decreased fat storage by Lactobacillus paracasei is associated with increased levels of angiopoietin-like 4 protein (ANGPTL4). PLOS ONE 5, e13087.

16. Kang JH, Yun SI \& Park HO (2010) Effects of Lactobacillus gasseri BNR17 on body weight and adipose tissue mass in diet-induced overweight rats. J Microbiol 48, 712-714.

17. Kondo S, Xiao JZ, Satoh T, et al. (2010) Antiobesity effects of Bifidobacterium breve strain B-3 supplementation in a mouse model with high-fat diet-induced obesity. Biosci Biotechnol Biochem 74, 1656-1661.

18. Takemura N, Okubo T \& Sonoyama K (2010) Lactobacillus plantarum strain No. 14 reduces adipocyte size in mice fed high-fat diet. Exp Biol Med 235, 849-856.

19. Fåk F \& Bäckhed F (2012) Lactobacillus reuteri prevents dietinduced obesity, but not atherosclerosis, in a strain dependent fashion in Apoe-/- mice. PLOS ONE 7, e46837.

20. Kang JH, Yun SI, Park MH, et al. (2013) Anti-obesity effect of Lactobacillus gasseri BNR17 in high-sucrose diet-induced obese mice. PLOS ONE 8, e54617.

21. Kim SW, Park KY, Kim B, et al. (2013) Lactobacillus rhamnosus GG improves insulin sensitivity and reduces adiposity in high-fat diet-fed mice through enhancement of adiponectin production. Biochem Biophys Res Commun 431, 258-263.

22. Okubo T, Takemura N, Yoshida A, et al. (2013) KK/Ta mice administered Lactobacillus plantarum strain No. 14 have lower adiposity and higher insulin sensitivity. Biosci Microbiota Food Health 32, 93-100.

23. Park DY, Ahn YT, Park SH, et al. (2013) Supplementation of Lactobacillus curvatus HY7601 and Lactobacillus plantarum KY1032 in diet-induced obese mice is associated with gut microbial changes and reduction in obesity. PLOS ONE $\mathbf{8}$, e59470.

24. Yoo SR, Kim YJ, Park DY, et al. (2013) Probiotics L. plantarum and L. curvatus in combination alter hepatic lipid metabolism and suppress diet-induced obesity. Obesity 21, 2571-2578.

25. Stenman LK, Waget A, Garret C, et al. (2014) Potential probiotic Bifidobacterium animalis ssp. lactis 420 prevents weight gain and glucose intolerance in diet-induced obese mice. Benef Microbes 5, 437-445.

26. Swinburn BA \& Ravussin E (1994) Energy and macronutrient metabolism. Baillieres Clin Endocrinol Metab 8, 527-548.

27. Spiegelman BM \& Flier JS (2001) Obesity and the regulation of energy balance. Cell 104, 531-543.

28. Ravussin E, Lillioja S, Anderson TE, et al. (1986) Determinants of 24-hour energy expenditure in man. Methods and results using a respiratory chamber. I Clin Invest $\mathbf{7 8}$, $1568-1578$.

29. Nagao K, Wang $\mathrm{YM}$, Inoue $\mathrm{N}$, et al. (2003) The 10trans, 12 cis isomer of conjugated linoleic acid promotes energy metabolism in OLETF rats. Nutrition 19, 652-656.

30. Nagao K, Jinnouchi T, Kai S, et al. (2013) Effect of dietary resveratrol on the metabolic profile of nutrients in obese OLETF rats. Lipids Health Dis 12, 8.
31. World Health Organization (1980) WHO Expert Committee on Diabetes Mellitus: second report. World Health Organ Tech Rep Ser 646, 1-80.

32. Calder PC, Ahluwalia N, Brouns F, et al. (2011) Dietary factors and low-grade inflammation in relation to overweight and obesity. Br J Nutr 106, S5-S78.

33. de Rekeneire N, Peila R, Ding J, et al. (2006) Diabetes, hyperglycemia, and inflammation in older individuals: the health, aging and body composition study. Diabetes Care 29, 1902-1908.

34. Nilsson J, Jovinge S, Niemann A, et al. (1998) Relation between plasma tumor necrosis factor-alpha and insulin sensitivity in elderly men with non-insulin-dependent diabetes mellitus. Arterioscler Thromb Vasc Biol 18, 1199-1202.

35. Fröhlich M, Imhof A, Berg G, et al. (2000) Association between C-reactive protein and features of the metabolic syndrome: a population-based study. Diabetes Care $\mathbf{2 3}$, 1835-1839.

36. American Institute of Nutrition (1977) Report of the American Institute of Nurtition ad hoc Committee on Standards for Nutritional Studies. J Nutr 107, 1340-1348.

37. Lo S, Russell JC \& Taylor AW (1970) Determination of glycogen in small tissue samples. J Appl Physiol 28, 234-236.

38. Han KH, Tsuchihira H, Nakamura Y, et al. (2013) Inulin-type fructans with different degrees of polymerization improve lipid metabolism but not glucose metabolism in rats fed a high-fat diet under energy restriction. Dig Dis Sci 58, $2177-2186$

39. Ley RE, Bäckhed F, Turnbaugh $\mathrm{P}$, et al. (2005) Obesity alters gut microbial ecology. Proc Natl Acad Sci U S A 102, 11070-11075.

40. Turnbaugh PJ, Ley RE, Mahowald MA, et al. (2006) An obesityassociated gut microbiome with increased capacity for energy harvest. Nature 444, 1027-1031.

41. Hara T, Kashihara D, Ichimura A, et al. (2014) Role of free fatty acid receptors in the regulation of energy metabolism. Biochim Biophys Acta 1841, 1292-1300.

42. Brown AJ, Goldsworthy SM, Barnes AA, et al. (2003) The Orphan G protein-coupled receptors GPR41 and GPR43 are activated by propionate and other short chain carboxylic acids. J Biol Chem 278, 11312-11319.

43. Bellahcene M, O'Dowd JF, Wargent ET, et al. (2013) Male mice that lack the G-protein-coupled receptor GPR41 have low energy expenditure and increased body fat content. Br J Nutr 109, 1755-1764.

44. Kimura I, Inoue D, Maeda T, et al. (2011) Short-chain fatty acids and ketones directly regulate sympathetic nervous system via G protein-coupled receptor 41 (GPR41). Proc Natl Acad Sci U S A 108, 8030-8035.

45. Gao Z, Yin J, Zhang J, et al. (2009) Butyrate improves insulin sensitivity and increases energy expenditure in mice. Diabetes 58, 1509-1517.

46. Baggio LL \& Drucker DJ (2007) Biology of incretins: GLP-1 and GIP. Gastroenterology 132, 2131-2157.

47. Tolhurst G, Heffron H, Lam YS, et al. (2012) Short-chain fatty acids stimulate glucagon-like peptide- 1 secretion via the G-protein-coupled receptor FFAR2. Diabetes 61, 364-371.

48. Cani PD, Dewever C \& Delzenne NM (2004) Inulin-type fructans modulate gastrointestinal peptides involved in appetite regulation (glucagon-like peptide-1 and ghrelin) in rats. BrJ Nutr $\mathbf{9 2}, 521-526$.

49. Cani PD, Neyrinck AM, Maton N, et al. (2005) Oligofructose promotes satiety in rats fed a high-fat diet: involvement of glucagon-like peptide-1. Obes Res 13, 1000-1007.

50. Parnell JA \& Reimer RA (2012) Prebiotic fibres dosedependently increase satiety hormones and alter 
Bacteroidetes and Firmicutes in lean and obese JCR:LA-cp rats. Br J Nutr 107, 601-613.

51. Michel O, Nagy AM, Schroeven M, et al. (1997) Dose-response relationship to inhaled endotoxin in normal subjects. Am J Respir Crit Care Med 156, 1157-1164.

52. Du Clos TW (2013) Pentraxins: structure, function, and role in inflammation. ISRN Inflamm 2013, 379040.

53. de Beer FC, Baltz ML, Munn EA, et al. (1982) Isolation and characterization of C-reactive protein and serum amyloid $\mathrm{P}$ component in the rat. Immunology $\mathbf{4 5}$, 55-70.

54. Koenig W (2007) Serum amyloid P component and cardiovascular disease: is there a sensible link? Arterioscler Thromb Vasc Biol 27, 698-700.
55. de Haas CJ, van der Tol ME, Van Kessel KP, et al. (1998) A synthetic lipopolysaccharide-binding peptide based on amino acids 27-39 of serum amyloid $\mathrm{P}$ component inhibits lipopolysaccharide-induced responses in human blood. J Immunol 161, 3607-3615.

56. de Haas CJ, van Leeuwen EM, van Bommel T, et al. (2000) Serum amyloid $\mathrm{P}$ component bound to gram-negative bacteria prevents lipopolysaccharide-mediated classical pathway complement activation. Infect Immun 68, 1753-1759.

57. Brüünsgaard H \& Pedersen BK (2003) Age-related inflammatory cytokines and disease. Immunol Allergy Clin North Am 23, 15-39.

58. Petersen AM \& Pedersen BK (2005) The anti-inflammatory effect of exercise. J Appl Physiol 98, 1154-1162. 